\title{
Opioid Prescribing Lessons Learned and Strategies to Minimize Trouble: Brief Commentary
}

\author{
Alan David Kaye, MD, PhD
}

Earlier this year, I wrote an editorial in Pain Physician on "Clinical and Professional Aspects of Prescribing for Pain Physicians (1)." The response was heartwarming and inspired me to create a detailed list of lessons learned in my practice of pain medicine. With all of the lectures we receive on disease, diagnosis, and drug mechanisms, it is most unfortunate that detailed practice management is often lacking in our education. In this regard, many state rules and regulations have changed considerably over the past decade in light of the amplified focus on opioid prescriptions, overdoses, and highlighted focus on pill mills and other practices with nefarious intentions. It is not surprising, therefore, that many physicians, including pain doctors, end up disciplined for easily avoidable offenses. Courses and webinars currently exist that every practitioner should utilize to avoid getting in trouble. If you have not attended a course or webinar in the past 12 months, you are in great jeopardy in your professional practice. Most doctors incorrectly think that if they are not sued or there is not a bad outcome, they are safe from investigation or prosecution. Often, simply lacking documentation, exceptions for certain patients made within your practice and innocent actions to help others may result in big trouble and potentially, the loss of your license to practice medicine. Even one violation can result in the loss of your license or disciplinary actions.

In this short commentary, common sense suggestions to minimize potential trouble from state boards and agencies such as the DEA are presented:

- Learn to say no to requests that are questionable or

Alan D. Kaye, MD, PhD

Editor-in-Chief, Pain Physician ASIPP \& ABIPP Board of Directors Professor, Program Director and Chairman, Department of Anesthesiology LSU School of Medicine

T6M5 1542 Tulane Ave., Room 656

New Orleans, LA 70112

Email: akaye@1suhsc.edu inappropriate. Many of us suffer from the condition of being people pleasers. You will still have plenty of patients, and your staff will respect you and not try to manipulate you, e.g., your nurse will not ask you for a prescription for her boyfriend who injured his foot, etc.

- Do not ever write a prescription for a secretary, a nurse, a partner, or a family member, including your parents, wife, and children. This includes antibiotics, blood pressure medication, testosterone, pain medications, sleep aides, cough syrups, or anything else. Regularly, physicians are reprimanded for prescribing to family members (even antibiotics) and additionally, not documenting with medical records, which is another violation

- Be precise with dates of prescriptions and do not fill medications early. Many patients will test you in order to see how they can manipulate you to receive additional medications

- Most states have opioid pill-count limits, typically an amount of 90 pills being the limit. This means that any prescription written for over 90 pills is most likely being "red-flagged" and could be part of a future complaint against you

- Cut your losses; patients who constantly attempt to violate rules or test negative for medication or positive for alcohol or illicit medications should not be given warnings, they should be discharged

- Patients who do not want to go to physical therapy, psychologists, or orthopedic consults should not be given warnings, they should be discharged from the clinic

- Generally, you should not prescribe benzodiazepines, unless there is a rare circumstance, e.g., the loss of a loved one and attendance at a funeral, etc. The Centers for Disease Control and Preventention Guidelines from last year recommend that opioids and benzodiazepines not be prescribed together (2). State boards will criticize the use of benzodiazepines and this practice has been seen in many complaints against pain specialists 
- Do not leave blank signed prescriptions ever

- Do not have your DEA number on your prescription. For example, if you are writing to have a consult or a radiological examination, there would be no need for your DEA number, which can be stolen

- If a patient tests negative for a drug, they should be asked to bring their medication for a pill count the next day, and if the count is off, they should be dismissed from the clinic

- Make policies in your clinic and follow them. For example, if a patient tests positive for a different opioid and you did not prescribe it, discharge the patient from your clinic

- If a patient does not answer his or her phone, they should be given one warning, as your opioid agreement should include that they must respond if you call them within 24 hours. Individual patients, knowing they are doing bad things, may not answer the phone. After one non-response, they should be dismissed from your clinic

- If you take over another doctor's patients who are on large doses of medication, you should immediately cut the doses down, not slowly titrate. Each prescription that you write over 90 pills or your state cut-off will be on you and your responsibility. If the patient is unwilling to cooperative, discharge the patient from your clinic

- Regularly, once a month, review your state board website for changes in practices related to pain medicine

- Urine drug screening should be done randomly, not at every visit

- Document the employment status of the patient and if the patient drove him/herself to their visit

- Utilize psychologists and psychiatrists on a regular basis. Many will communicate that an individual patient is not appropriate for opioids

- Do not back-date or future-date a prescription

- Realize that tolerance to pain relief with opioids is uncommon

- If you decide to increase an opioid dose, you need to document the reason, e.g., the patient had increased pain after their injection, etc.

- If a patient is on a fentanyl patch, look and document that they have it on their body, which should be on the trunk or abdomen, not the extremities. If needed, make the patient bring in old patches

- Routinely document the time the patient last took their medicine. The answer of the patient may warrant a drug test

- Best practice suggests providing oral opioids 17 hours after taking an opioid patch off

- In evaluating treatment outcomes, consider the 5 As- analgesia, activities of daily living, adverse effects, aberrant behavior, and affect

- Write "cancer pain" on the prescription when large doses of an opioid are prescribed. Often, a pharmacy can file a complaint or help initiate an investigation on a prescriber, therefore, have good communication with them and always be cordial

- Often, pharmacists have limits on the dosage of narcotics, and when these are exceeded, it triggers a more critical review that may identify abuse patterns. These reviews often include speaking with the prescriber for specific clarification as to the need of a larger dosage of medication or a broader discussion on a specific patient's condition, etc.

- Realize that fentanyl is often not measured on typical urine testing

- Appreciate that after one month of opioids, there may be increased pain from increased activity

- Focus on things that a patient can fix, such as cessation of smoking, weight loss, and exercise

- Do not work with an unethical partner, he or she will alter your boundaries and the result will be that you will be disciplined and regret it

- Have balance with your family and hobbies. The person who only works has more difficulty with boundaries and the potential for professional trouble.

Many of these best strategies can be found in a number of detailed reviews found in our special opioid issue in March, 2017 (3-5). I welcome comments and suggest taking a course on prescribing opioids to be completed by every pain physician. These courses are pre-approved by state medical boards, which list those that they feel meet their standards. There are also many other educational opportunities available through the American Society of Interventional Pain Physicians to prevent trouble in your professional future, including focused opioid prescribing courses. 
Opioid Prescribing Lessons Learned and Strategies to Minimize Trouble

\section{REFERENCES}

1. Kaye AD. Clinical and professional aspects of opioid prescribing for pain physicians. Pain Physician 2017; 20:S1-S2.

2. Dowell D, Haegerich TM, Chou R. CDC Guideline for prescribing opioids for chronic pain — United States, 2016. MMWR Recomm Rep 2016; 65:1-49.

3. Kaye AD, Jones MR, Kaye AM, Ripoll JG, Galan V, Beakley BD, Calixto F, Bolden JL, Urman RD, Manchikanti L. Prescription opioid abuse in chronic pain: An updated review of opioid abuse predictors and strategies to curb opioid abuse: Part 1. Pain Physician 2017; 20:S93-S109.

4. Kaye AD, Jones MR, Kaye AM, Ripoll JG, Jones DE, Galan V, Beakley BD, Calixto F, Bolden JL, Urman RD, Manchikanti L. Prescription opioid abuse in chronic pain: An updated review of opioid abuse predictors and strategies to curb opioid abuse (part 2). Pain Physician 2017; 20:S111-S133.

5. Manchikanti L, Kaye AM, Knezevic NN, McAnally H, Slavin K Trescot AM, Blank S, Pampati V, Abdi S, Grider JS, Kaye AD, Manchikanti KN, Cordner H, Gharibo CG, Harned ME, Albers SL, Atluri S, Aydin SM, Bakshi S, Barkin RL, Benyamin RM, Boswell MV, Buenaventura RM, Calodney AK, Cedeno DL, Datta S, Deer TR, Fellows B, Galan V, Grami V, Hansen H, Helm li S, Justiz R, Koyyalagunta D, Malla Y, Navani A, Nouri KH, Pasupuleti R, Sehgal N, Silverman SM, Simopoulos TT, Singh V, Solanki DR, Staats PS, Vallejo R, Wargo BW, Watanabe A, Hirsch JA. Responsible, safe, and effective prescription of opioids for chronic non-cancer pain: American Society of Interventional Pain Physicians (ASIPP) Guidelines. Pain Physician 2017; 20:S3-S92. 
IPM Reports 